\title{
Repeated Intranasal Flumazenil Administration in Adult Subjects During Prolonged Benzodiazepine-induced Sedation
}

\author{
Trevor J. Szymanski ${ }^{1}$, Michael D. Curley ${ }^{2}$, Mirjana M. Lovrincevic ${ }^{3}$, Beverly K. Philip ${ }^{1}$, JuliWyle- \\ gala $^{4}$ and Massimo Ferrigno ${ }^{1, *}$ \\ ${ }^{1}$ Department of Anesthesiology, Perioperative and Pain Medicine, Brigham and Women's Hospital, Boston, MA, USA \\ ${ }^{2}$ Center for Research and Education in Special Environments (CRESE) and Department of Physiology and Biophysics, \\ University at Buffalo, Buffalo, NY, USA \\ ${ }^{3}$ Department of Anesthesiology, Roswell Park Cancer Institute, Buffalo, NY, USA \\ ${ }^{4}$ Rehabilitation Science, University at Buffalo, Buffalo, NY, USA
}

\begin{abstract}
As part of a study exploring the use of oral diazepam to reduce carbon dioxide production and extend survival in a disabled submarine, intranasal flumazenil was used repeatedly over 48 hours to intermittently reverse benzodiazepineinduced sedation in six adult male subjects. Previous reports of intranasal flumazenil have been limited to pediatric patients. Here we report the time course of administration of intranasal flumazenil and its effects on adult subjects, in whom flumazenil was given during sedation/reversal/re-sedation cycles. Sedation scores increased with flumazenil administration in 24 of the 30 cycles, and in 100\% of cases when subjects were at deeper levels of sedation.
\end{abstract}

Keywords: Diazepam, large doses, benzodiazepines, benzodiazepine antagonist, sedation/reversal/re-sedation cycles, alternative route.

\section{INTRODUCTION}

Although the U.S. Food \& Drug Administration has only approved intravenous administration of flumazenil, there are reports in the pediatric literature of successful intranasal [1, 2] and rectal administration [3, 4] of this competitive benzodiazepine antagonist. In adults, flumazenil has been successfully administered by inhalation via endotracheal tube [5]. However, there is no report of intranasal flumazenil administration in adults in the medical literature, only an internet summary of a graduate student thesis [6].

As part of a study exploring the use of a benzodiazepine (diazepam) to reduce carbon dioxide production and extend survival in a disabled submarine, intranasal flumazenil was used repeatedly over 48 hours to intermittently reverse sedation in adult subjects [7]. That study showed a $13-15 \%$ decrease in both oxygen consumption and carbon dioxide production, which was thought to result mainly from the $30 \%$ decrease in body movement observed in the sedated subjects. Here we report the time course of the administration of intranasal flumazenil and its effects on young healthy adults.

*Address correspondence to this author at the Department of Anesthesiology, Perioperative and Pain Medicine, Brigham \& Woman's Hospital, 75 Francis Street, Boston, MA 02115, USA; Tel: 617-732-8749;

Fax:617-277-2192; E-mail: maxmd@aol.com

\section{METHODS}

Six healthy male subjects volunteered for the study referenced in this Short Communication. The study was approved by the University of Buffalo Health Science Institutional Review Board. During the 48-hour drug phase of this study (which followed a placebo phase of the same duration),three subjects at a time (Group I with Subjects 1, 2 and 3; Group II with Subjects 4,5 and 6) were kept at bed rest in a controlled laboratory setting. These settings were designed to mimic the conditions faced by the crew in a stable, unpowered submarine. Subjects were blinded as to whether they were receiving placebo or diazepam. After initial oral (PO) doses of 10 to $40 \mathrm{mg}$ of diazepam, additional increments of $5,10,20$, or $30 \mathrm{mg}$ PO of diazepam were administered every 30 to 60 minutes to achieve sedation corresponding to an Observer's Assessment of Alertness/Sedation Scale (OAA/S) of 3 or 4 [8]. The OAA/S scale was chosen for ease of use, with a score of " 3 " indicating that the subject responded only after name was called loudly or repeatedly, "4" that the subject exhibited a lethargic response to name spoken in a normal tone, and "5" that the subject was alert, responding to name spoken in a normal tone. At the beginning of this study, the two participating anesthesiologists simultaneously observed three sedated subjects over several hours, showing perfect agreement between their independent assessments of OAA/S scores. 
Using a needle-less $3 \mathrm{ml}$ syringe, intranasal flumazenil $(0.1 \mathrm{mg} / \mathrm{ml})$ was administered during the drug phase of the study at intervals spanning 8.5 to 11.75 hours, and at the end of the experiment (3 hours after the last reversal). Flumazenil was given as drops through one or both nostrils at least 30 minutes before a scheduled cognitive test, which was used to assess effectiveness of Flumazenil in reversing sedation on mental alertness, attention, memory and mood (cf. 7). An initial dose of either 0.1 or $0.2 \mathrm{mg}$ was administered; if full alertness had not been restored, as determined by the OAA/S scale, additional intranasal flumazenil doses of $0.1-0.2 \mathrm{mg}$ were given every 5 minutes until full alertness was achieved.

The subjects were continuously monitored throughout the experiments by laboratory staff, and evaluated at least every hour by an in-house anesthesiologist. In addition to oxygen consumption and carbon dioxide production, heart rate, arterial oxygen saturation, arterial blood pressure, respiratory rate and tympanic temperature were measured every hour, and their body movements were continuously recorded by a wrist worn accelerometer (cf. 7). At the end of the study, the subjects were kept under observation for 6 hours in the laboratory prior to discharge home in the care of an adult, and followed with phone calls at 24 and 72 hours.

\section{RESULTS}

Vital signs did not exhibit any discernable changes. Table 1 shows both hourly and total diazepam doses, as well as flumazenil doses given for each of the five sedation/awakening cycles during the experiments. Overall, the second group of three subjects received more diazepam during 48 hours than the first group (an average of 468 vs. 380 $\mathrm{mg}$ ), as the investigators became more confident using larger doses. Intranasal doses of flumazenil ranged from 0.1 to 0.6 mg. Table 2 shows the OAA/S scores before and after each flumazenil administration. After the 30 intranasal administrations, OAA/S scores increased in twenty-four cases,and they remained the same in six cases; when subjects were at deeper levels of sedation (OAA/S scores less than 4), these scores increased in $100 \%$ of cases after flumazenil administration. No side effects of flumazenil were reported by the six subjects or noted by the observers after all reversals from sedation. The subjects also took a battery of tests to document the effects of sedation and reversal on mental alertness, attention, memory and mood, and the results of these tests have already been reported [7]. At the time of their discharge home, the subjects were found to be oriented to time and place, in good spirits, but also reporting fatigue and napping intermittently. At the 24-hour telephone follow up, the subjects still reported symptoms of sedation, while at the 72hour telephone follow up they reported that they were back to normal condition and activities.

\section{DISCUSSION}

To our knowledge, this is the first report in the medical literature of the use of intranasal flumazenil to reverse sedation in healthy adult humans. This new route was effectively and repeatedly used in six adult subjects over the course of prolonged sedation, awakening and re-sedation cycles, during our 48 hour-long study. Incidentally, our experimental study also included the largest doses of PO diazepam, administered over 48 hours in healthy adults, reported in the medical literature. Larger doses of PO diazepam have only been reported for the treatment of schizophrenia (up to 400 mg PO per day) [9]. For the mechanisms of action of both benzodiazepines and their antagonists, see review by Philip [10].

A two-page summary of a Korean dental school thesis available on the internet [6] describes the use of intranasal

Table 1. Dosing Summary for Diazepam and Flumazenil

\begin{tabular}{|c|c|c|c|c|c|c|c|c|c|c|}
\hline \multirow{2}{*}{$\begin{array}{c}\text { Sub- } \\
\text { ject }\end{array}$} & \multicolumn{2}{|c|}{ Cycle 1} & \multicolumn{2}{|c|}{ Cycle 2} & \multicolumn{2}{|c|}{ Cycle 3} & \multicolumn{2}{|c|}{ Cycle 4} & \multicolumn{2}{|c|}{ Cycle 5} \\
\hline & $\begin{array}{c}\text { Diazepam } \\
\text { mg/hr } \\
\text { (total } \mathrm{mg} \text { ) }\end{array}$ & $\begin{array}{c}\text { Flumazenil } \\
\text { mg }\end{array}$ & $\begin{array}{c}\text { Diazepam } \\
\text { mg/hr } \\
\text { (total mg) }\end{array}$ & $\begin{array}{c}\text { Flumazenil } \\
\text { mg }\end{array}$ & $\begin{array}{c}\text { Diazepam } \\
\text { mg/hr } \\
\text { (total mg) }\end{array}$ & $\begin{array}{c}\text { Flumazenil } \\
\text { mg }\end{array}$ & $\begin{array}{c}\text { Diazepam } \\
\text { mg/hr } \\
\text { (total } \mathrm{mg} \text { ) }\end{array}$ & $\begin{array}{c}\text { Flumazenil } \\
\text { mg }\end{array}$ & $\begin{array}{c}\text { Diazepam } \\
\text { mg/hr } \\
\text { (total mg) }\end{array}$ & $\begin{array}{c}\text { Flu- } \\
\text { mazenil } \\
\text { mg }\end{array}$ \\
\hline 1 & $\begin{array}{l}12.55 \\
(135)\end{array}$ & 0.4 & $4.74(45)$ & 0.3 & $9.41(80)$ & 0.1 & $\begin{array}{l}14.44 \\
(130)\end{array}$ & 0.6 & $9.23(30)$ & 0.2 \\
\hline 2 & $\begin{array}{l}11.00 \\
(110)\end{array}$ & 0.4 & $4.74(45)$ & 0.3 & $9.41(80)$ & 0.2 & $10(105)$ & 0.6 & $6.67(20)$ & 0.4 \\
\hline 3 & 9.30 (100) & 0.4 & 3.68 (35) & 0.3 & $9.41(80)$ & 0.1 & $\begin{array}{l}12.82 \\
(125)\end{array}$ & 0.6 & $6.15(20)$ & 0.3 \\
\hline 4 & $\begin{array}{l}13.02 \\
(140)\end{array}$ & 0.3 & 9.47 (90) & 0.4 & $4.71(40)$ & 0.3 & 10.5 (105) & 0.6 & $12.31(40)$ & 0.4 \\
\hline 6 & $\begin{array}{l}15.81 \\
(170)\end{array}$ & 0.3 & 9.47 (90) & 0.3 & $8.24(70)$ & 0.3 & 10.5 (105) & 0.6 & $12.31(40)$ & 0.4 \\
\hline
\end{tabular}


Table 2. Summary of Observer's Assessment of Alertness/Sedation Scale Scores

\begin{tabular}{|c|c|c|c|c|c|c|c|c|c|c|}
\hline & \multicolumn{2}{|c|}{ Sedation 1 } & \multicolumn{2}{c|}{ Sedation 2 } & \multicolumn{2}{c|}{ Sedation 3 } & \multicolumn{2}{c|}{ Sedation 4 } & \multicolumn{2}{c|}{ Sedation 5 } \\
\hline & $\begin{array}{c}\text { Before } \\
\text { Reversal }\end{array}$ & $\begin{array}{c}\text { After Re- } \\
\text { versal }\end{array}$ & $\begin{array}{c}\text { Before } \\
\text { Reversal }\end{array}$ & $\begin{array}{c}\text { After Re- } \\
\text { versal }\end{array}$ & $\begin{array}{c}\text { Before } \\
\text { Reversal }\end{array}$ & $\begin{array}{c}\text { After Re- } \\
\text { versal }\end{array}$ & $\begin{array}{c}\text { Before } \\
\text { Reversal }\end{array}$ & $\begin{array}{c}\text { After Re- } \\
\text { versal }\end{array}$ & $\begin{array}{c}\text { Before } \\
\text { Reversal }\end{array}$ & $\begin{array}{c}\text { After } \\
\text { Reversal }\end{array}$ \\
\hline \hline 1 & 4 & 4 & 4 & 5 & 5 & 5 & 3.5 & 5 & 5 \\
\hline 2 & 3 & 5 & 4 & 5 & 4.5 & 5 & 3.5 & 5 & 4 & 5 \\
\hline 3 & 4 & 4 & 4 & 5 & 4.5 & 5 & 4 & 4.5 & 5 \\
\hline 4 & 4 & 4.5 & 3 & 5 & 4 & 5 & 4 & 4.5 & 4 \\
\hline 5 & 4 & 4.5 & 3 & 5 & 4 & 5 & 4 & 4.5 & 4 & 5 \\
\hline 6 & 4.5 & 4.5 & 3 & 5 & 4 & 5 & 4 & 5 & 4 \\
\hline
\end{tabular}

flumazenil to reverse sedation induced by midazolam (0.08 $\mathrm{mg} / \mathrm{kg}$ intravenously) in 25 young, healthy volunteers. In their experiments, $0.5 \mathrm{mg}$ of flumazenil was administered intranasally as a $5 \mathrm{ml}$ solution over 1 minute. Similar to what we described, no significant changes in vital signs (heart rate, respiratory rate, arterial blood pressure, arterial oxygen saturation and body temperature) were observed. Pharmacokinetic analysis showed that the peak serum flumazenil concentration occurred 10 minutes after the intranasal administration of this benzodiazepine antagonist. A study describing flumazenil administration to 11 pediatric patients under general anesthesia used a much larger dose (40 $\mathrm{mcg} / \mathrm{kg}$ ), based on the assumed $50 \%$ bioavailability of this medication through this route of administration [2]. These investigators found that the maximal plasma flumazenil concentration occurred 2 minutes after its intranasal administration. This difference in time course, compared to the thesis above [6], may be due to the larger dose of intranasal flumazenil used in the pediatric patients. The authors of this pediatric study also concluded that the mean plasma concentrations of flumazenil following intranasal administration were similar to those attained after intravenous administration and that they should be sufficient to antagonize the sideeffects of benzodiazepines in children. Effective reversal was clinically observed in all subjects of our study (see Table 2), compared to 2 of the 25 subjects of the Korean thesis [6].

The reported side effects from flumazenil include, in decreasing order of incidence, nausea, tremors, involuntary movements, dizziness, agitation, discomfort, tears, anxiety, agitation, headache, blurred vision and dyspnea/hyperventilation [10]. None of these side effects were reported by our subjects. Also, no paradoxical reactions to diazepam such as excitement, excessive movement, emotional release, hostility or rage [11] were observed, despite the use of large doses. In both instances, this could be due to our small sample size, the fact that our subjects were young and healthy, and to the slow administration and titration of flumazenil, which is known to minimize its side effects [10].

The sedation/reversal/re-sedation cycles that we describe in this report may have clinical relevance during awake craniotomies, in patients undergoing insertion and testing of spinal cord, motor cortex or deep brain stimulators and in intensive care patients whose neurological status may need to be evaluated intermittently over the course of hours or days. Spontaneous re-sedation can be expected from the much shorter half-life of flumazenil (0.7-1.3 hours); [12]) vs. diazepam (43 +/- 13 hours; [13]). During our experiments, re-sedation was intentionally augmented with additional diazepam, until the conclusion of the experimental session when it took longer than 24 hours for our subjects to return to their normal baseline neurological condition. If midazolam had been used (with an elimination half-life of 1.5 2.4 hours) [14], it would have resulted in faster clinical recovery after sedation/reversal/re-sedation cycles, although re-sedation may also occur with midazolam [15].

The intranasal route for administration of medications in adult patients is also used for both naloxone [16] and for midazolam [17] when intravenous access has not yet been established or may be difficult, and when PO administration may not be practical. As reported in this study, a similar approach may be used for flumazenil to reverse sedation induced by benzodiazepines, for example in the emergency department. Alternative routes of flumazenil administration include sublingual, intramuscular and rectal, which appear to be as effective but slower than the intravenous route in reversing benzodiazepine-induced respiratory depression [18]. Risks of intranasal delivery of medications include laryngospasm and aspiration, leading some authors to suggest that patients be placed in Trendelenburg position during intranasal drug administration; this suggestion may not apply to adult patients. In most of their pediatric patients, Scheepers et al. divided the flumazenil dose equally between each nostril [2], as we also did in our experiments. This approach, compared to the whole dose administered through one nostril, may maximize absorption by the nasal mucosa, while minimizing oral and gastric absorption and first pass hepatic metabolism [19]. In general, nasal absorption of medications is better when administered in smaller volumes [14].

Our observations, originating from a non-clinical study of six healthy adult subjects, suggest that the intranasal administration of flumazenil is effective in reversing sedation induced by benzodiazepines. Therefore, this approach may be useful clinically in adult patients without an intravenous access. 


\section{CONFLICT OF INTERSEST}

The authors confirm that this article content has no conflicts of interest.

\section{ACKNOWLEDGEMENT}

This study was funded by United States Navy.

\section{REFERENCES}

[1] Heard C, Creighton P, Lerman J. Intranasal flumazenil and naloxone to reverse over-sedation in a child undergoing dental restorations. Pediatric Anesth 2009; 19: 795-9.

[2] Scheepers LD, Montgomery CJ, Kinahan AM, et al. Plasma concentration of flumazenil following intranasal administration in children. Can J Anaesth 2000; 47(2): 120-4.

[3] Lopez-Herce. J, Lopez de Sa E, Garcia de Frias E. Reversal of midazolam sedation with rectal flumazenil in children. Crit Care Med 1994; 22: 1204.

[4] Carbajal R, Simon N, Blanc P, et al. Rectal flumazenil to reverse midazolam sedation in children. Anesth Analg 1996; 82: 895.

[5] Palmer RB, Mautz DS, Cox K, et al. Endotracheal flumazenil: a new route of administration for benzodiazepine antagonism. Am J Emerg Med 1998; 16(2): 170-2.

[6] http://s-space.snu.ac.kr/pdfupload/0000860861.pdf

[7] Curley MD, Ferrigno M, Lovrincevic MM, et al. Extending submarine crew survival by reducing $\mathrm{CO} 2$ production with quickly reversible sedation. Aviat Space Environ Med 2010; 81: 537-44.
[8] Chernik DA, Gillings D, Laine H, et al. Validity and reliability of the observer's assessment of alertness/sedation scale: study with intravenous midazolam. J Clin Psychopharmacol 1990; 10: 244-5.

[9] Beckmann H, Haas S. High dose diazepam in schizophrenia. Psychopharmacology 1980; 71(1): 79-82.

[10] Philip B. Drug Reversal: Benzodiazepine receptors and antagonists. J Clin Anesth 1993; 5(1): 46s-51s.

[11] Hall RW, Zisook S. Paradoxical reactions to benzodiazepines. Br J Clin Pharmacol 1981; 11: 99-104S.

[12] Klotz U, Kanto J. Pharmacokinetics and clinical use of flumazenil. Clin Pharmaco-kinet 1988; 14: 1-1.

[13] Charney D, Mihic SJ, Harris RA. Hypnotics and sedatives. In: Shanahan J, Foltin J, Edmonson K, Brown Y, Eds: Goodman \&Gillmans's The Pharmacological Basis of Therapeutics. New York: The McGraw Hill Co., Inc. 2006: pp. 401-28.

[14] Amrein R, Hetzel W. Pharmacology of Dormicum (midazolam) and Anexate (flumazenil). Acta Anaesthesiol Scand 1990; 92(Suppl.): 6-15.

[15] Philip BK, Simpson TS, Hauch MA, et al. Flumazenil reverses sedation after midazolam-induced general anesthesia in ambulatory surgery patients. Anesth Analg 1990; 71: 371-6.

[16] Kelly AM, Kerr D, Dietze P, et al. Randomised trial of intranasal versus intramuscular naloxone in prehospital treatment for suspected opioid overdose. Med J Aust 2005; 182(1): 24-7.

[17] Uygur-Bayramicli O, Dabak R, Kuzucuoglu T, et al. Sedation with intranasal midazolam in adults undergoing upper gastrointestinal endoscopy. J Clin Gastroenterol 2002; 35(2): 133-7.

[18] Henif MS, Moore GP, Trout A, et al. Comparison of routs of flumazenil administration to reverse midazolam-induced respiratory depression in a canine model. Acad Emerg Med 1997; 4: 1115-8.

[19] Klotz U, Kanto J. Pharmacokinetics and clinical use of Flumazenil (RO15-1788). Clin Pharmacokinet 1988; 14; 1-12. 